\title{
DESAIN PEMBELAJARAN KONSTEKSTUAL SPIRIT MEDA MAZI DI SD KELAS RENDAH
}

\author{
Dek Ngurah Laba Laksana \& Maria Angelina Seso \\ STKIP Citra Bakti, Nusa Tenggara Timur, Indonesia \\ laba.laksana@citrabakti.ac.id
}

\begin{abstract}
Abstrak
Tujuan dari penulisan ini adalah untuk mengembangkan desain pembelajaran kontekstual spirit meda mazi di kelas rendah. Model pembelajaran kontekstual merupakan pembelajaran yang dilakukan oleh guru, untuk mengaitkan antara materi yang diajarkan dengan situasi dunia nyata siswa dan mendorong siswa membuat hubungan antara pengetahuan yang dimiliki dengan penerapannya dalam kehidupan mereka sehari-hari baik lingkungan pribadi, sosial dan budayanya. Spirit meda mazi merupakan ungkapan dalam bahasa Bajawa yang artinya duduk bersama untuk membicarakan sesuatu yang bermanfaat (bermusyawarah). Pengumpulan data penulisan ini dengan pendekatan deskriptif melalui wawancara, observasi dan riview literatur. Berdasarkan wawancara yang dilakukan dengan para guru di SDI Malanuza, bahwa dalam implementasi penerapan model pembelajaran kotentekstual yang berbasis spirit meda mazi guru masih mengalami kesulitan, yaitu dalam mengkaji materi. Karena tidak semua materi pembelajaran dapat diterapkan dengan menggunakan model pembelajaran ini. Model pembelajaran yang berbasis kontekstual spirit meda mazi saat ini baru diterapkan di dua Kecamatan yang ada di Kabupaten Ngada yaitu Kecamatan Golewa dan Kecamatan Golewa Selatan khususnya di sekolah dasar. Pembelajaran yang berbasis kontekstual spirit meda mazi ini dikembangkan berdasarkan hal-hal yang berkaitan dengan pelajaran di sekolah dengan hal-hal yang dipelajari di lingkungan masyarakat. Pembelajaran yang berbasis kontekstual spirit meda mazi yang diterapakan di kelas rendah sangat membantu guru pada saat menjelaskan materi pelajaran. Karena pada pembelajaraan guru dapat menggunakan bahasa keseharian siswa yaitu bahasa daerah yang dapat membantu guru untuk menjelaskan materi sehingga siswa dapat lebih mudah untuk memahami materi yang diajarkan.
\end{abstract}

Kata Kunci: spirit meda mazi, pembelajaran kontekstual

\begin{abstract}
The aimed of this paper is to develop the contextual learning design of mazi meda strategy in base class. Contextual learning model is a learning done by the teacher, to relate between the material taught to the real world situation of the students and encourage students to make connections between the knowledge they have with their application in their daily life both personal, social and cultural environment. Mazi mazi strategy is an expression in the language of Bajawa which means sitting together to talk about something useful (cooperative). The data collection of this writing with descriptive approach through interviews, observation and riview literature. Based on interviews conducted with teachers in SDI Malanuza, that in the implementation of the application of kotentekstual learning model based on spirit meda mazi teachers still have difficulty, namely in reviewing the material. Because not all learning materials can be applied using this learning model. Contextual learning model based on the spirit of mazi meda is currently only applied in two sub districts in Ngada District, Golewa District and South Golewa District, especially in elementary school. Contextual based learning meda mazi strategy is developed based on matters relating to lessons in school with the things learned in the community. Contextual based learning meda mazi strategy applied in the base class is very helpful when teachers explain the subject matter. Because the learning of teachers can use the language of everyday students is the vernacular language that can help teachers to explain the material so that students can more easily to understand the material being taught.
\end{abstract}

Keywords: meda mazi, contextual learning 


\section{Pendahuluan}

Undang-undang Nomor 20 Tahun 2003 tentang Pendidikan Nasional menyatakan bahwa pendidikan adalah usaha sadar dan terencana untuk mewujudkan suasana belajar dan proses pembelajaran agar peserta didik secara aktif mengembangkan potensi dirinya untuk memiliki kekuatan spiritual keagamaan, pengendalian diri, kepribadian, kecerdasan, akhlak mulia, serta keterampilan yang diperlukan dirinya, masyarakat, bangsa dan negara. Pendidikan Nasional menurut undang-undang bertujuan untuk untuk mengembangkan potensi peserta didik agar menjadi manusia yang beriman dan bertaqwa kepada Tuhan Yang Maha Esa, berakhlak mulia, sehat, berilmu, cakap, kreatif, mandiri, dan menjadi warga negara yang demokratis serta bertanggung jawab.

Masalah pendidikan di Indonesia tidak terlepas dari kurangnya kesadaran masyarakat akan pentingnya pendidikan. Oleh karena itu, pemerintah Indonesia harus mampu mengatasi dan menanggapi kendala-kendala mengenai pendidikan yang ada di Indonesia sehingga dapat diminimalisir. Usaha yang dilakukan oleh tenaga pendidik di Indonesia adalah memperbaiki proses belajar dan mengajar. Pendidikan disekolah merupakan lembaga tempat dimana terjadi proses sosialisasi yang kedua setelah mempengaruhi pribadi anak dan perkembangan sosialnya.

Dasna, dkk (2015) menyatakan bahwa model pembelajaran kontekstual adalah konsep belajar yang mengaitkan antara materi yang diajarkan dengan situasi dunia nyata anak dan mendorong anak untuk membuat hubungan antara pengetahuan yang dimilikinya dengan penerapan dalam kehidupan sehari-hari.

Menurut Slavin (2005) mengatakan Contextual Teaching and Learning merupakan suatu konsepsi yang membantu guru menghubungkan konten materi ajar dengan situasi-situasi dunia nyata dan memotivasi siswa untuk membuat hubungan antara pengetahuan dan penera pannya ke dalam kehidupan mereka sebagai anggota keluarga, warga negara, dan tenaga kerja.

Lebih lanjut, pendekatan kontekstual merupakan konsep belajar yang dapat membantu guru mengaitkan antara materi yang diajarkan dengan situasi dunia nyata siswa dan mendorong siswa untuk membuat hubungan antara pengetahuan yang dimilikinya dengan penerapannya dalam kehidupannya mereka sebagai anggota keluarga dan masyarakat. Dari ketiga pendapat di atas dapat disimpulkan pembelajaran kontekstual merupakan pembelajaran yang dilakukan oleh guru, untuk mengaitkan antara materi yang diajarkan dengan situasi dunia nyata siswa dan mendorong siswa membuat hubungan antara pengetahuan yang dimiliki dengan penerapannya dalam kehidupan mereka sehari-hari baik lingkungan pribadi, sosial dan budayanya.

Meda mazi merupakan model pembelajaran yang baru diterapkan di sekolah dasar (Lagong, 2017). Beberapa SD di Kecamatan Golewa, Kabupaten Ngada, NTT, saat ini sedang menerapakn model pembelajaran kotekstual yang berbasis spirit meda mazi, dalam proses pembelajaran. Dalam hal ini guru harus banyak memiliki kreatifitas yang tinggi untuk mencapai tujuan pembelajaran yang telah di tentukan. Namun dalam penerapan model pembelajaran kotekstual yang berbasis spirit meda mazi ini, guru masih mengalami kendala dalam mengkaji karena tidak semua materi dapat menggunakan model pembelajaran ini. Jadi guru harus lebih teliti dalam mengkaji materi. Desain pembelajaran dengan menggunakan model kontekstual yang berbasis spirit meda mazi yaitu kompetensi inti, kompetensi dasar, indikator, tujuan, materi, kegiatan kontekstual, pengetahuan yang ditambahkan, kunci kreatif, langkah-langkah pembelajaran dan penilaian. Dalam tulisan ini, mengkaji bagaimana mendesain pembelajaran kontekstual dengan spirit Meda mazi dan kesahihan pembelajaran tersebut dalam meningkatkan hasil belajar siswa SD.

\section{Metode}

Penelitian ini adalah penelitian deskriptif. Pengumpulan data penelitian ini melalui wawancara, observasi dan riview literatur. Penulisan ini untuk penelaan desain pembelajaran kotekstual spirit meda mazi di kelas rendah.

\section{Hasil dan Pembahasan}

Berdasarkan wawancara yang dilakukan dengan para guru di SD Kecamatan Golewa, bahwa dalam penerapan model pembelajaran kotentekstual yang berbasis spirit meda mazi masih mengalami 
kesulitan, yaitu dalam mengkaji materi. Karena tidak semua materi pembelajaran dapat diterapakan dengan menggunakan model pembelajaran ini.

Dengan menerapakan model pembelajaran kontekstual siswa dapat mengalami langsung, sehingga dapat membuat para siswa lebih cepat memahami materi yang diajarkan dibandingkan dengan cara mengafal. Oleh sebab itu pembelajaran kontekstual yang berbasis spirit meda mazi dapat lebih cepat merangsang daya pikir atau nalar siswa pada saat pembelajaran berlangsung, sehingga siswa terlibat aktif pada saat pembelajaran itu berlangsung. Dalam proses pembelajaran, guru harus menyusun langkahlangkah pembelajaran sesuai dengan karakteristik siswa. Guru hanya sebagai fasilitator sedangkan siswa lebih berperan aktif dalam proses pembelajaran. Pada saat pembelajaran berlangsung, jika temuan siswa belum tepat maka guru yang meluruskan kembali jawaban siswa sesuai dengan indikator yang telah di tentukan. Proses pembelajaran kontekstual yang berbasis spirit meda mazi di Kabupaten Ngada hanya dilaksanakan di kecamatan Golewa dan Golewa selatan untuk jenjang sekolah dasar. Dua Kecamatan ini menjalin kerja sama dengan wahana visi Indonesia (Jogjakarta), yang mengadopsi karakter daerah kedalam lembaga pendidikan dasar.

\section{Kesahihan Pembelajaran Kontekstual Spirit Meda Mazi}

Pembelajaran kontekstual dengan spirit meda mazi merupakan pembelajaran yang dilakukan oleh guru, untuk mengaitkan antara materi yang diajarkan dengan situasi dunia nyata siswa dan mendorong siswa membuat hubungan antara pengetahuan yang dimiliki dengan penerapannya dalam kehidupan mereka sehari-hari baik lingkungan pribadi, sosial dan budayanya (Lagong dkk, 2017).

Meda mazi merupakan ungkapan dalam bahasa Bajawa yang artinya duduk bersama untuk membicarakan sesuatu yang bermanfaat (bermusyawarah). Pembelajaran dengan spirit meda mazi identik dengan pembelajaran dengan pendekatan kooperatif. dimana dalam pembelajaran tersebut, siswa didorong untuk belajar dalam kelompok diskusinya (Eggen \& Kauchak, 2012). Model pembelajaran yang berbasis kontekstual spirit meda mazi saat ini baru diterapkan di dua Kecamatan yaitu Kecamatan Golewa dan Kecamatan Golewa Selatan khususnya di sekolah dasar (SD). Pembelajaran yang berbasis kontekstual spirit meda mazi ini di kembangkan berdasarkan hal-hal yang berkaitan dengan pelajaran di sekolah dengan hal-hal yang dipelajari di lingkungan masyarakat. Model pembelajaran ini sangat erat hubungannya dengan model pembelajaran kooperatif. Model pembelajaran kooperatif adalah pendekatan pembelajaran yang berfokus pada penggunaan kelompok kecil siswa untuk bekerja sama dalam memamaksimalkan kondisi belajar untuk mencapai tujuan belajar (Slavin, 2005).

Menurut Laksana dan Rabu (2016) bahwa pembelajaran kontekstual dapat meningkatkan hasil belajar siswa. Karena pada pembelajaran kontekstual siswa dapat mengalami atau melihat secara langsung situasi dunia nyata siswa dan mendorong siswa membuat hubungan antara pengetahuan yang dimiliki dengan penerapannya dalam kehidupan mereka sehari-hari baik lingkungan pribadi, sosial dan budayanya.

Desain pembelajaran dengan menggunakan model kontekstual spirit meda mazi yaitu Proses pembelajaran yang dirancang agar peserta didik lebih berperan secara aktif dan kreatif mengembangkan potensi dirinya dan potensi lingkungan untuk memiliki kekuatan spiritual keagamaan, pengendalian diri, kepribadian, kecerdasan, akhlak mulia, serta keterampilan yang diperlukan dirinya, masyarakat, bangsa, dan negara. Proses pembelajaran pada satuan pendidikan diselenggarakan secara interaktif, inspiratif, menyenangkan, menantang, memotivasi peserta didik untuk berpartisipasi aktif, serta memberikan ruang yang cukup bagi prakarsa, kreativitas, dan kemandirian sesuai dengan bakat, minat, dan perkembangan fisik serta psikologis peserta didik. Pengembanganya secara harmonis melalui keseimbangan antara olah hati/etik, olah piker/literais, olah rasa/estetika, olah raga/kinestetik. Serta harus didasari melalui revolusi mental yang merupakan perubahan relatif yang cepat dalam cara berpikir dalam merespon, bertindak dan bekerja.

\section{Desain Pembelajaran Kontekstual Spirit Meda mazi}

Satu Rencana Pelaksanaan Pembelajaran (RPP) dilaksanakan dalam satu kali pertemuan (satu hari), karena dalam penerapan kurikulum 2013 telah ditentukan bahwa satu pembelajaran terdiri dari 3-4 mata pelajaran yang akan diajarkan (Tematik).

Pembelajaran di desain secara utuh memuat kompetensi dasar, sikap spiritual (KD dari KI1), sosial (KD dari KI-2), pengetahuan (KD dari KI-3), dan keterampilan (KD dari KI-4), ini merupakan kompetensi inti dari suatu rancangan pembelajaran untuk melihat hasil belajar dari sikap spiritual, sikap sosial, sikap pengetahuan dan sikap keterampilan. Memperhatikan perbedaan individu 
peserta didik. Rencana Pelaksanaan Pembelajaran (RPP) disusun dengan memperhatikan perbedaan kemampuan awal, tingkat intelektual, minat, motivasi belajar, bakat, potensi, kemampuan sosial, emosi, gaya belajar, kebutuhan khusus, kecepatan belajar, latar belakang budaya, norma, nilai, dan/atau lingkungan peserta didik, sehingga dapat tercapai tujuan pembelajaran yang telah ditentukan.

Pembelajaran Kontekstual Spirit Meda mazi di desain agar berpusat pada peserta didik. Proses pembelajaran dirancang dengan berpusat pada peserta didik untuk mendorong motivasi, minat, kreativitas, inisiatif, inspirasi, kemandirian, dan semangat belajar, menggunakan pendekatan saintifik meliputi mengamati, menanya, mengumpulkan informasi, menalar/mengasosiasi, dan mengomunikasikan. Desain pembelajaran juga berbasis kontekstual. Proses pembelajaran yang menjadikan lingkungan sekitarnya sebagai sumber belajar, karena pembelajaran kontekstual merupakan pembelajaran yang dilakukan oleh guru, untuk mengaitkan antara materi yang diajarkan dengan situasi dunia nyata siswa dan mendorong siswa membuat hubungan antara pengetahuan yang dimiliki dengan penerapannya dalam kehidupan mereka sehari-hari baik lingkungan pribadi, sosial dan budayanya. Pembelajaran selalu berorientasi kekinian. Pembelajaran yang berorientasi pada pengembangan ilmu pengetahuan dan teknologi, dan nilai-nilai kehidupan masa kini, guru yang berorientasi kekinian adalah guru yang tidak gagap teknologi. Desain pembelajaran dikembangkan dengan menekankan pada kemandirian belajar. Pembelajaran yang memfasilitasi peserta didik untuk belajar secara mandiri, sehingga dalam hal ini dapat mengukur tingkat pemahaman yang dimiliki siswa.

Memberikan umpan balik dan tindak lanjut pembelajaran. Rencana Pelaksanaan Pembelajaran (RPP) memuat rancangan program pemberian umpan balik positif, penguatan, pengayaan, dan remedial, hal ini dapat menguji kembali sejauh mana pemahaman siswa terhadap materi yang diajarkan dan apabila sebagian besar siswa belum mencapai ketuntasan hasil belajar yang diinginkan maka guru akan mengulang kembali materi yang sudah diajarkan.

Memiliki keterkaitan dan keterpaduan antar kompetensi dan/atau antar muatan pembelajaran. Rencana Pelaksanaan Pembelajaran (RPP) disusun dengan memperhatikan keterkaitan dan keterpaduan antara KI, KD, indikator pencapaian kompetensi, materi pembelajaran, kegiatan pembelajaran, penilaian, dan sumber belajar dalam satu keutuhan pengalaman belajar. Rencana Pelaksanaan Pembelajaran (RPP) disusun dengan mengakomodasikan pembelajaran tematik, keterpaduan lintas mata pelajaran, lintas aspek belajar, dan keragaman budaya.

Memanfaatkan teknologi informasi dan komunikasi. Rencana Pelaksanaan Pembelajaran (RPP) disusun dengan mempertimbangkan penerapan teknologi informasi dan komunikasi secara terintegrasi, sistematis, dan efektif sesuai dengan situasi dan kondisi nyata. Sebagai contoh ketika guru menugasi siswa mengekslorasikan sumber-sumber pengetahuan melalui internet.

Rencana Pelaksanaan Pembelajaran berbasis Kontekstual (RPPBK) spirit meda mazi merupakan rencana pembelajaran yang dikembangkan secara rinci mengacu pada silabus, buku teks pelajaran, dan buku panduan guru. Rencana Pelaksanaan Pembelajaran (RPP) paling sedikit memuat: 1) identitas sekolah/madrasah, kelas/semester, tema dan subtema, pembelajaran ke, alokasi waktu, tanggal pelaksanaan dan KKM. 2) KI, KD, indikator pencapaian kompetensi, 3) tujuan pembelajaran, 4) materi pembelajaran, 5) nama dan deskripsi kegiatan kontekstual, 6) pokok pikiran spirit kontekstual, 7) kegiatan pembelajaran, 8) kunci kreatif, 9) alat, bahan, dan sumber belajar, 10) penilaian.

Guru diwajibkan untuk membuat rencana pelaksanaan pembelajaran (RPP), sebelum pembelajaran itu dilaksanakan. Pengembangan RPP dapat di lakukan oleh guru secara mandiri dan/atau berkelompok di sekolah dikoordinasi, difasilitasi, dan disupervisi oleh kepala sekolah.

\section{Simpulan}

Model pembelajaran kontekstual merupakan pembelajaran yang dilakukan oleh guru, untuk mengaitkan antara materi yang diajarkan dengan situasi dunia nyata siswa dan mendorong siswa membuat hubungan antara pengetahuan yang dimiliki dengan penerapannya dalam kehidupan mereka sehari-hari baik lingkungan pribadi, sosial dan budayanya.

Meda mazi merupakan ungkapan dalam bahasa bajawa yang artinya duduk bersama untuk membicarakan sesuatu yang bermanfaat (bermusyawarah). SDI Malanuza saat ini sedang menerapakn model pembelajaran kotekstual yang berbasis spirit meda mazi, dalam proses pembelajaran. Dalam hal ini guru harus banyak memiliki kreatifitas yang tinggi untuk mencapai tujuan pembelajaran yang telah di tentukan.

Desain Pembelajaran Konstekstual Spirit Meda Mazi di SD Kelas Rendah 
Desain pembelajaran dengan menggunakan model kontekstual spirit meda mazi yaitu Proses pembelajaran yang dirancang agar peserta didik lebih berperan secara aktif dan kreatif mengembangkan potensi dirinya dan potensi lingkungan untuk memiliki kekuatan spiritual keagamaan, pengendalian diri, kepribadian, kecerdasan, akhlak mulia, serta keterampilan yang diperlukan dirinya, masyarakat, bangsa, dan negara. Proses pembelajaran pada satuan pendidikan diselenggarakan secara interaktif, inspiratif, menyenangkan, menantang, memotivasi peserta didik untuk berpartisipasi aktif, serta memberikan ruang yang cukup bagi prakarsa, kreativitas, dan kemandirian sesuai dengan bakat, minat, dan perkembangan fisik serta psikologis peserta didik. Pengembanganya secara harmonis melalui keseimbangan antara olah hati/etik, olah pikir/literais, olah rasa /estetika, olah raga/kinestetik. Serta harus didasari melalui revolusi mental yang merupakan perubahan relatif yang cepat dalam cara berpikir dalam merespon, bertindak dan bekerja.

\section{Daftar Rujukan}

Dasna, I W., Laksana, D.N.L., \& Sudhata, I G.W. (2015). Desain dan Model Pembelajaran Inovatif dan Interaktif. Jakarta: Universitas Terbuka Press.

Eggen, P. \& Kauchak, D. (2012). Strategie and Models for Teachers: Teaching Content and Thinking Skill, Ed. $\sigma^{\text {th }}$. Boston; Pearson

Lagong, A., Juita, E. \& Laksana, D.N.L. (2017). Desain Pembelajaran Kontekstual Spirit Kearifan Lokal Medamazi untuk Siswa Sekolah Dasar. Prosiding. $2^{\text {nd }}$ Annual Proceeding, November 2017 (ISSN: 2355-5106) STKIP Citra Bakti, Bajawa, NTT.

Laksana, D.N.L \& Rabu, K. (2016). Pembelajaran Kontekstual Berbantuan LKS Dalam Upaya Meningkatkan Pemahaman Konsep IPA dan Aktivitas Belajar Siswa SD. Jurnal Pendidikan Citra Bakti, 2(1), 79-89.

Slavin, R.E. (2005). Cooperative Learning: theory, research, and practice. London: Allymand Bacon 